Review Article

\title{
Neonatal Resuscitation Research Priorities in Low- and Middle- Income Countries
}

\author{
Vivek V. Shukla $\mathbb{D}^{1,2}$ and Somashekhar M. Nimbalkar $\mathbb{D}^{2}$ \\ ${ }^{1}$ University of Alabama at Birmingham, Birmingham, Alabama, USA \\ ${ }^{2}$ Bhaikaka University, Karamsad, Gujarat, India \\ Correspondence should be addressed to Vivek V. Shukla; viveks3985@gmail.com
}

Received 25 July 2021; Revised 5 November 2021; Accepted 15 November 2021; Published 25 November 2021

Academic Editor: Lavjay Butani

Copyright (C) 2021 Vivek V. Shukla and Somashekhar M. Nimbalkar. This is an open access article distributed under the Creative Commons Attribution License, which permits unrestricted use, distribution, and reproduction in any medium, provided the original work is properly cited.

\begin{abstract}
Several critical physiological changes occur during birth. Optimal and timely resuscitation is essential to avoid morbidity and mortality. The International Liaison Committee on Resuscitation (ILCOR) is a multinational committee that publishes evidence-based consensus and treatment recommendations for resuscitation in various scenarios including that for neonatal resuscitation. The majority of perinatal deaths occur in low- and middle-income countries (LMICs); however, there is limited research output from LMICs to generate evidence-based practice recommendations specific for LMICs. The current review identifies key areas of neonatal resuscitation-related research needed from LMICs to inform evidence-based resuscitation of neonates in LMICs.
\end{abstract}

\section{Introduction}

Extrauterine transition at birth and survival depends on several critical interlinked physiologic changes, including increase in systemic vascular resistance, decrease in pulmonary vascular resistance, closure of right to left shunts, alveolar fluid absorption and clearance, increase in metabolic demand, and endocrine changes [1-4]. The extrauterine transition in term newborns occurs spontaneously in about 85\% [5], 10\% need stimulation [6], 5\% need positive pressure ventilation, $2 \%$ need intubation, and $0.1 \%$ need chest compressions [7, 8]. Cardiopulmonary resuscitation is needed for a relatively small proportion of newborns [7]; however, the absolute number is high when seen in the context of the total number of births [9]. Timely and appropriate resuscitation can prevent long-term morbidity and neonatal death $[5,10,11]$.

\section{Resuscitation Guidelines}

The International Liaison Committee on Resuscitation (ILCOR) is a committee of 8 international resuscitation councils, the majority of which are from high-income countries, which publishes evidence-based consensus and treat- ment recommendations for neonatal resuscitation [12, 13]. The most recent guidelines are the 2020 International Consensus on Cardiopulmonary Resuscitation (CPR) and Emergency Cardiovascular Care (ECC) Science with Treatment Recommendations (CoSTR) for neonatal life support (NLS) with thorough evidence evaluation (Table 1) [14].

2.1. Perinatal Mortality in Low- and Middle-Income Countries. The global perinatal and neonatal deaths are estimated to be 4 million per year, and of that, about $98 \%$ occur in low- and middle-income countries (LMICs) [15-17]. Despite the sustained focus on reducing neonatal mortality by various international and local health organizations, neonatal deaths have increased in the relative contribution for under-5 child deaths [18]. Intrapartum asphyxia accounts for about 2 million stillbirths and neonatal deaths/year [17, 19-21] and results in long-term neurodevelopmental disabilities in about 1 million survivors/year [22] with a loss of about 41 million disability-adjusted life years/year [23]. Failure to initiate breathing after birth is the primary reason for death and disability in infants with birth asphyxia [24]. Lack of access to optimal resuscitation at birth is a preventable 
TABLE 1: 2020 CoSTR topics reviewed and evidence evaluation process [14].

\begin{tabular}{|c|c|c|c|c|}
\hline $\begin{array}{l}\text { Sr. } \\
\text { no. }\end{array}$ & Topic & Subtopic & Process & $\begin{array}{l}\text { Studies from } \\
\text { LMICs }\end{array}$ \\
\hline \multirow{2}{*}{1} & \multirow{2}{*}{ Anticipation and preparation } & $\begin{array}{c}\text { Prediction of need of respiratory support in the delivery } \\
\text { room }\end{array}$ & Evidence update & No \\
\hline & & $\begin{array}{l}\text { Effect of briefing/debriefing following neonatal } \\
\text { resuscitation }\end{array}$ & Scoping review & No \\
\hline \multirow{3}{*}{2} & \multirow{3}{*}{ Initial assessment and intervention } & Warming adjuncts & Evidence update & No \\
\hline & & Suctioning of clear fluid & Scoping review & No \\
\hline & & $\begin{array}{l}\text { Tracheal intubation and suction of nonvigorous } \\
\text { meconium-stained newborns }\end{array}$ & Systematic review & Yes \\
\hline 3 & $\begin{array}{l}\text { Physiological monitoring and } \\
\text { feedback devices }\end{array}$ & Heart rate monitoring during neonatal resuscitation & Evidence update & No \\
\hline \multirow{6}{*}{4} & \multirow{6}{*}{ Ventilation and oxygenation } & Sustained inflation & Systematic review & Yes \\
\hline & & Positive end-expiratory pressure (PEEP) versus no PEEP & Evidence update & No \\
\hline & & $\begin{array}{c}\text { Continuous positive airway pressure (CPAP) versus } \\
\text { intermittent PPV }\end{array}$ & Evidence update & No \\
\hline & & $\begin{array}{l}\text { T-piece resuscitator versus self-inflating bag for } \\
\text { ventilation }\end{array}$ & Scoping review & Yes \\
\hline & & Oxygen for preterm resuscitation & $\begin{array}{l}2019 \text { CoSTR } \\
\text { publication }\end{array}$ & No \\
\hline & & Oxygen for term resuscitation & $\begin{array}{l}2019 \text { CoSTR } \\
\text { publication }\end{array}$ & No \\
\hline \multirow[b]{2}{*}{5} & \multirow[b]{2}{*}{ Circulatory support } & $\mathrm{CPR}$ ratios for neonatal resuscitation & Evidence update & No \\
\hline & & $\begin{array}{l}\text { 2-thumb versus 2-finger compressions for neonatal } \\
\text { resuscitation }\end{array}$ & Evidence update & No \\
\hline \multirow{4}{*}{6} & \multirow{4}{*}{ Drug and fluid administration } & Epinephrine (adrenaline) for neonatal resuscitation & Systematic review & No \\
\hline & & Intraosseous versus umbilical vein for emergency access & Systematic review & No \\
\hline & & Volume infusion during neonatal resuscitation & Evidence update & No \\
\hline & & Sodium bicarbonate during neonatal resuscitation & Evidence update & No \\
\hline 7 & Prognostication during CPR & Impact of duration of intensive resuscitation & Systematic review & No \\
\hline \multirow{3}{*}{8} & \multirow{3}{*}{ Postresuscitation care } & Rewarming of hypothermic newborns & Evidence update & No \\
\hline & & Induced hypothermia in settings with limited resources & Evidence update & Yes \\
\hline & & Postresuscitation glucose management & Evidence update & No \\
\hline
\end{tabular}

cause of death that is responsible for the majority of the perinatal and neonatal deaths in LMICs $[10,11,25]$.

2.2. Resuscitation-Related Research in LMICs. The majority of resuscitation-related research that informs ILCOR neonatal resuscitation recommendations is from high-income countries. In the current ILCOR NLS-CoSTR, only 20 of a total of 96 of the referenced original science studies are from LMICs [14], and the majority of them are small sample size studies that have a limited grade of evidence. Interventional research can help identify the best management approach for a given disease or condition. This highlights the urgent need for enhancing resuscitation-related research for improving perinatal and neonatal outcomes in LMICs.

2.3. Why More Resuscitation-Related Research Is Needed from LMICs. The evidence from interventional research is specific for the environment and patient characteristics that it is tested and cannot be simply extrapolated to other settings. The research from high-income countries may not be applicable to low resource settings of LMICs because of differences in nutritional, environmental, socioeconomic, and genetic factors. Also, the ancillary resources and trained healthcare providers needed for a specific intervention may not be available. The application of the intervention without appropriate monitoring and follow-up may result in an increase in the risk of adverse outcomes. For example, several therapeutic hypothermia trials from high-income countries show benefits in survival and neurodevelopmental outcomes [26-28], establishing its role as a standard of care in infants with perinatal hypoxic-ischemic encephalopathy in high-income countries. However, as shown in the recently completed therapeutic hypothermia trial from LMICs, including infants from public sector neonatal units, infants in the therapeutic hypothermia group had increased mortality without any difference in severe disability in survivors 
[29]. This finding highlights the importance of validating research from high-income countries by evaluating them in LMICs before their routine adoption in LMICs. In order to successfully conduct interventional trials for neonatal resuscitation in LMICs, specific attention has to be directed at adequate funding for securing appropriate resources, training of healthcare personnel, and trial oversight for ensuring the protection of trial participants. After assessing the effectiveness of interventions, prior to adoption for a given setting, availability of adequately trained healthcare providers and availability of resources should be ensured, as resources and healthcare provider availability may differ between individual settings within LMICs [30-34]. Interventions should be carefully introduced while monitoring the responses for ongoing effectiveness evaluation and health policy insights needed for analyzing public health improvements and optimal resource allocation and utilization.

2.4. Areas of Resuscitation-Related Research Needing More Evidence from LMICs. Insufficient evidence from LMICs has led to knowledge gaps that are major barriers to the improvement of perinatal and neonatal outcomes in LMICs. There are several areas of neonatal resuscitation-related research that need better evidence from LMICs. Some of the research gaps include optimal oxygenation targets for resuscitation of preterm infants, therapeutic hypothermia for infants with perinatal depression from centers with higher levels of care, delivery of respiratory support at specific gestational age groups and testing of various interfaces, optimal thresholds, method, route, doses, and timing of various resuscitation-related interventions like chest compressions, epinephrine, volume expanders, and inotropes [14]. As outcomes of infants who are enrolled in interventional trials and the survivors getting admitted for intensive care may not be representative of the overall population, it is also essential to set up a collaborative registry of infants needing resuscitation at delivery from multiple institutes to better evaluate the outcomes of all infants with various conditions and those receiving different interventions. In addition to reporting hospital outcomes, efforts should be made to evaluate the long-term outcomes of infants enrolled in interventional trials, including 2-year neurodevelopmental and school-age outcomes using standardized assessment tools.

2.5. Future Directions. There needs to be a sustained effort towards improving the amount and quality of neonatal resuscitation-related research for informing evidence-based strategies from LMICs. Strengthening research infrastructure and supporting investigators with enhanced governmental and philanthropic research funding can help support quality neonatal research from LMICs. The creation of international, national, and interinstitutional research networks for collaboration, peer evaluation of research projects, and monitoring of ongoing projects can help streamline research efforts in LMICs. Efforts targeted towards training and mentoring early career investigators from LMICs can harness and promote the expertise and training needed for neonatal research.

\section{Data Availability}

No original data was used in the current review.

\section{Conflicts of Interest}

All authors have indicated they have no potential conflicts of interest to disclose.

\section{Authors' Contributions}

VVS conceptualized and drafted the initial manuscript and reviewed and revised the manuscript. SMN conceptualized, reviewed, and revised the manuscript. All authors approved the final manuscript for submission and agree to be accountable for all aspects of the work.

\section{References}

[1] A. Finnemore and A. Groves, "Physiology of the fetal and transitional circulation," Seminars in Fetal \& Neonatal Medicine, vol. 20, no. 4, pp. 210-216, 2015.

[2] J. R. Swanson and R. A. Sinkin, "Transition from fetus to newborn," Pediatric Clinics of North America, vol. 62, no. 2, pp. 329-343, 2015.

[3] Y. Gao and J. U. Raj, "Regulation of the pulmonary circulation in the fetus and newborn," Physiological Reviews, vol. 90, no. 4, pp. 1291-1335, 2010.

[4] N. H. Hillman, S. G. Kallapur, and A. H. Jobe, "Physiology of transition from intrauterine to extrauterine life," Clinics in Perinatology, vol. 39, no. 4, pp. 769-783, 2012.

[5] H. L. Ersdal, E. Mduma, E. Svensen, and J. M. Perlman, "Early initiation of basic resuscitation interventions including face mask ventilation may reduce birth asphyxia related mortality in low-income countries: a prospective descriptive observational study," Resuscitation, vol. 83, no. 7, pp. 869-873, 2012.

[6] H. L. Ersdal, J. Linde, E. Mduma, B. Auestad, and J. Perlman, "Neonatal outcome following cord clamping after onset of spontaneous respiration," Pediatrics, vol. 134, no. 2, pp. 265272,2014

[7] D. E. Niles, C. Cines, E. Insley et al., "Incidence and characteristics of positive pressure ventilation delivered to newborns in a US tertiary academic hospital," Resuscitation, vol. 115, pp. 102-109, 2017.

[8] C. Halling, J. E. Sparks, L. Christie, and M. H. Wyckoff, "Efficacy of intravenous and endotracheal epinephrine during neonatal cardiopulmonary resuscitation in the delivery room," The Journal of Pediatrics, vol. 185, pp. 232-236, 2017.

[9] Australian Institute of Health and Welfare, Australia's Mothers and Babies 2017-In Brief, AIHW, Canberra, 2017, https://www.aihw.gov.au/getmedia/2a0c22a2-ba27-4ba0ad47-ebbe51854cd6/aihw-per-100-in-brief.pdf.aspx?inline= true.

[10] Z. A. Bhutta, J. K. Das, R. Bahl et al., "Can available interventions end preventable deaths in mothers, newborn babies, and stillbirths, and at what cost?," Lancet, vol. 384, no. 9940, pp. 347-370, 2014.

[11] J. E. Lawn, H. Blencowe, R. Pattinson et al., "Stillbirths: where? When? Why? How to make the data count?," Lancet, vol. 377, no. 9775, pp. 1448-1463, 2011. 
[12] D. Chamberlain, "The International Liaison Committee on Resuscitation (ILCOR)-Past and present: Compiled by the Founding Members of the International Liaison Committee on Resuscitation," Resuscitation, vol. 67, no. 2-3, pp. 157161, 2005.

[13] "International Liaison Committee on Resuscitation," https:// www.ilcor.org.

[14] M. H. Wyckoff, J. Wyllie, K. Aziz et al., "Neonatal life support: 2020 international consensus on cardiopulmonary resuscitation and emergency cardiovascular care science with treatment recommendations," Circulation, vol. 142, 16_suppl_1, pp. S185-S221, 2020.

[15] V. V. Shukla and W. A. Carlo, "Review of the evidence for interventions to reduce perinatal mortality in low- and middle-income countries," International Journal of Pediatrics and Adolescent Medicine, vol. 7, no. 1, pp. 2-8, 2020.

[16] H. Blencowe, S. Cousens, F. B. Jassir et al., "National, regional, and worldwide estimates of stillbirth rates in 2015, with trends from 2000: a systematic analysis," The Lancet Global Health, vol. 4, no. 2, pp. e98-e108, 2016.

[17] L. Liu, S. Oza, D. Hogan et al., "Global, regional, and national causes of child mortality in 2000-13, with projections to inform post-2015 priorities: an updated systematic analysis," Lancet, vol. 385, no. 9966, pp. 430-440, 2015.

[18] R. Burstein, N. J. Henry, M. L. Collison, L. B. Marczak, A. Sligar, and S. Watson, "Mapping 123 million neonatal, infant and child deaths between 2000 and 2017," Nature, vol. 574, no. 7778, pp. 353-358, 2019.

[19] Estimation UNI-aGfCM, United Nations Inter-agency Group for Child Mortality Estimation, Levels \& Trends in Child Mortality: Report 2020, Estimates developed by the United Nations Inter-agency Group for Child Mortality Estimation: United Nations Children's Fund, New York; New York, 2020, https://www.unicef.org/media/79371/file/UN-IGME-childmortality-report-2020.pdf.pdf04/30/2021.

[20] J. E. Lawn, H. Blencowe, S. Oza et al., "Every newborn: progress, priorities, and potential beyond survival," Lancet, vol. 384, no. 9938, pp. 189-205, 2014.

[21] H. Wang, C. A. Liddell, M. M. Coates et al., "Global, regional, and national levels of neonatal, infant, and under-5 mortality during 1990-2013: a systematic analysis for the Global Burden of Disease Study 2013," Lancet, vol. 384, no. 9947, pp. 957979, 2014.

[22] N. Al-Macki, S. P. Miller, N. Hall, and M. Shevell, “The spectrum of abnormal neurologic outcomes subsequent to term intrapartum asphyxia," Pediatric Neurology, vol. 41, no. 6, pp. 399-405, 2009.

[23] R. E. Black, S. Cousens, H. L. Johnson et al., "Global, regional, and national causes of child mortality in 2008: a systematic analysis," Lancet, vol. 375, no. 9730, pp. 19691987, 2010.

[24] A. C. C. Lee, S. Cousens, S. N. Wall et al., "Neonatal resuscitation and immediate newborn assessment and stimulation for the prevention of neonatal deaths: a systematic review, metaanalysis and Delphi estimation of mortality effect," BMC Public Health, vol. 11, Supplement 3, p. S12, 2011.

[25] G. L. Darmstadt, A. C. C. Lee, S. Cousens et al., "60 million non-facility births: who can deliver in community settings to reduce intrapartum-related deaths?," International Journal of Gynaecology and Obstetrics, vol. 107, Supplement, pp. S89112, 2009.
[26] S. Shankaran, A. R. Laptook, R. A. Ehrenkranz et al., "Wholebody hypothermia for neonates with hypoxic-ischemic encephalopathy," The New England Journal of Medicine, vol. 353, no. 15, pp. 1574-1584, 2005.

[27] P. D. Gluckman, J. S. Wyatt, D. Azzopardi et al., "Selective head cooling with mild systemic hypothermia after neonatal encephalopathy: multicentre randomised trial," Lancet, vol. 365, no. 9460, pp. 663-670, 2005.

[28] D. V. Azzopardi, B. Strohm, A. D. Edwards et al., "Moderate hypothermia to treat perinatal asphyxial encephalopathy," The New England Journal of Medicine, vol. 361, no. 14, pp. 1349-1358, 2009.

[29] S. Thayyil, S. Pant, P. Montaldo et al., "Hypothermia for moderate or severe neonatal encephalopathy in low-income and middle-income countries (HELIX): a randomised controlled trial in India, Sri Lanka, and Bangladesh," The Lancet Global Health, vol. 9, no. 9, pp. e1273-e1285, 2021.

[30] Organization WH, Postnatal Care for Mothers and Newborns, Highlights from the World Health Organization 2013 guidelines, RHR/15.05, Geneva, 2015.

[31] UNICEF, State of the world's children: celebrating 20 years of the convention on the rights of the child, UNICEF, 2009.

[32] S. N. Wall, A. C. C. Lee, S. Niermeyer et al., "Neonatal resuscitation in low-resource settings: what, who, and how to overcome challenges to scale up?," International Journal of Gynecology \& Obstetrics, vol. 107, Supplement, pp. S47-S64, 2009.

[33] A. Manasyan, S. Saleem, M. Koso-Thomas et al., "Assessment of obstetric and neonatal health services in developing country health facilities," American journal of perinatology., vol. 30, no. 9, pp. 787-794, 2013.

[34] M. Kouo-Ngamby, F. N. Dissak-Delon, I. Feldhaus, C. Juillard, K. A. Stevens, and M. Ekeke-Monono, "A cross-sectional survey of emergency and essential surgical care capacity among hospitals with high trauma burden in a Central African country," BMC health services research, vol. 15, no. 1, 2015. 